\title{
High prevalence of autoantibodies to RNA helicase A in Mexican patients with systemic lupus erythematosus
}

\author{
Monica Vázquez-Del Mercado ${ }^{1,2}$, Claudia A Palafox-Sánchez', Jose F Muñoz-Valle ${ }^{1}$, Gerardo Orozco-Barocio ${ }^{3}$, \\ Edith Oregon-Romero ${ }^{1}$, Rosa E Navarro-Hernández ${ }^{1}$, Mario Salazar-Páramo ${ }^{4}$, Juan Armendariz-Borunda ${ }^{5}$, \\ Jorge I Gámez-Nava ${ }^{4}$, Laura Gonzalez-Lopez ${ }^{6}$, Jason YF Chan${ }^{7}$ Edward KL Chan ${ }^{8}$, Minoru Satoh ${ }^{7,{ }^{*}}$
}

\begin{abstract}
Introduction: Autoantibodies to RNA helicase A (RHA) were reported as a new serological marker of systemic lupus erythematosus (SLE) associated with early stage of the disease. Anti-RHA and other autoantibodies in Mexican SLE patients and their correlation with clinical and immunological features were examined.
\end{abstract}

Methods: Autoantibodies in sera from 62 Mexican SLE patients were tested by immunoprecipitation of ${ }^{35}$ S-labeled K562 cell extract and enzyme-linked immunosorbent assay (anti-U1RNP/Sm, ribosomal P, $\beta 2 \mathrm{GPI}$, and dsDNA). AntiRHA was screened based on the immunoprecipitation of the 140-kDa protein, the identity of which was verified by Western blot using rabbit anti-RHA serum. Clinical and immunological characteristics of anti-RHA-positive patients were analyzed.

Results: Anti-RHA was detected in 23\% (14/62) of patients, a prevalence higher than that of anti-Sm (13\%, 8/62). Prevalence and levels of various autoantibodies were not clearly different between anti-RHA (+) vs. (-) cases, although there was a trend of higher levels of anti-RHA antibodies in patients without anti-U1RNP/Sm $(P=0.07)$. Both anti-RHA and -Sm were common in cases within one year of diagnosis; however, the prevalence and levels of anti-RHA in patients years after diagnosis did not reduce dramatically, unlike a previous report in American patients. This suggests that the high prevalence of anti-RHA in Mexican patients may be due to relatively stable production of anti-RHA.

Conclusions: Anti-RHA was detected at high prevalence in Mexican SLE patients. Detection of anti-RHA in races in which anti-Sm is not common should be clinically useful. Racial difference in the clinical significance of anti-RHA should be clarified in future studies.

\section{Introduction}

Systemic autoimmune rheumatic diseases such as systemic lupus erythematosus (SLE), scleroderma (systemic sclerosis), and polymyositis/dermatomyositis are serologically characterized by the production of autoantibodies to cellular constituents [1,2]. Although autoantibodies target various proteins, protein complexes, proteinnucleic acid complexes, and nucleic acids, selection of the target antigens is not a random event; rather, there

\footnotetext{
* Correspondence: Minoru.Satoh@medicine.ufl.edu

${ }^{7}$ Division of Rheumatology and Clinical Immunology, Department of Medicine, University of Florida, 1600 SW Archer Road, Gainesville, FL 326100424, USA
}

can be a tight link between the specificity of autoantibodies each patient produces and the diagnosis or certain clinical symptoms. Some of the specificities are detected almost exclusively in patients with certain clinical diagnosis and considered pathognomonic. Anti-Sm and double-stranded DNA (dsDNA) antibodies are highly specific for the diagnosis of SLE and are included in the classification criteria [3]. While anti-dsDNA antibodies are found in approximately $70 \%$ of patients with SLE, their production fluctuates depending on the lupus activity and treatment they receive. Production of anti$\mathrm{Sm}$ antibodies is generally considered more stable and is found in approximately $15 \%$ of patients with SLE; 
however, it is common in African-Americans and is low in prevalence in Caucasians [4]. Anti-ribosomal P and anti-PCNA (proliferating cell nuclear antigen) antibodies found in approximately $10 \%$ and approximately $2 \%$ of patients with SLE also are considered specific for SLE [1]. We have recently reported that, in addition to these classic markers, autoantibodies to RNA helicase A (RHA, also known as DNA helicase II), a 3'-5' dsDNA/ RNA helicase [5] that belongs to the DExH superfamily of helicases, are a new serological marker of SLE $[1,4]$. In the previous report, the rates of prevalence of antiRHA were $6 \%(8 / 133)$ in Caucasians, $2.9 \%(3 / 103)$ in African-Americans, and $12 \%(3 / 25)$ in the Latin population in the US. Another earlier report was also from the US [6]. Except for preliminary data suggesting that approximately $10 \%$ of Japanese patients with SLE are also positive [7], anti-RHA in other countries has not been reported. Anti-RHA is also unique in that it is associated with the early stage of the disease, typically within a year of diagnosis of SLE. However, the number in the Latin population was too small to analyze in the previous study [4]. In the present study, we determined the prevalence of anti-RHA and examined the clinical and immunological characteristics of anti-RHA-positive Mexican patients with SLE.

\section{Materials and methods Patients}

Sixty-two consecutive patients with SLE from the Department of Rheumatology, Hospital General de Occidente, Zapopan, Jalisco, Mexico, were studied. All patients fulfilled the 1982 American College of Rheumatology (ACR) SLE classification criteria [3]. Mex-SLEDAI (Mexican Systemic Lupus Erythematosus Disease Activity Index) and Systemic Lupus International Collaborating Clinics/ACR Damage Indexes at the beginning of the study were evaluated [8,9]. Complete blood count, including lymphocyte count and serum rheumatoid factor (CELL-DYN 3500R; Abbott Diagnostics, Chicago, IL, USA), was determined in all subjects. Information on treatment of the day of sampling, including use of immunosuppressive drugs (azathioprine, methotrexate, and cyclophosphamide), chloroquine, and dose of steroid (milligrams of prednisone per day), was recorded. The protocol was approved by the institutional review board. This study meets and is in compliance with all ethical standards in medicine, and written informed consent was obtained from all patients according to the Declaration of Helsinki.

\section{Screening of autoantibodies in human sera by immunoprecipitation}

Immunoprecipitation (IP) using ${ }^{35} \mathrm{~S}$-methionine-labeled K562 cell extract to determine IgG class autoantibodies was performed using $8 \mu \mathrm{L}$ of sera as described [10]. Specificities such as anti-U1RNP, Sm, ribosomal P, Ro, La, $\mathrm{Ku}$, argonaute $2(\mathrm{Ago} 2) / \mathrm{Su}$, and RNA polymerase II (RNAP II) were verified using previously described reference sera. Positive anti-U1RNP was defined based on the presence of the set of U1RNP proteins (A, B'/B, C, D1/D2/D3, E/F, and G). Since autoantibodies to U5RNP without anti-Sm are very rare [11], IP of the characteristic U5RNP 200-kDa proteins was used to define anti-Sm (which immunoprecipitates U2, U4-6, and U5 in addition to U1RNP) [10].

Anti-RHA was first screened based on IP of the 140$\mathrm{kDa}$ protein. Selected sera were then re-run on $8 \%$ SDSPAGE to verify that the mobility of the $140-\mathrm{kDa}$ protein was the same as that of RHA immunoprecipitated by the reference sera. The identity of the $140-\mathrm{kDa}$ protein as RHA was further confirmed by IP-Western blot (WB) as previously described [12]. Briefly, non-radiolabeled K562 cell extract from $5 \times 10^{6}$ cells was immunoprecipitated with $2 \mu \mathrm{L}$ of serum that immunoprecipitated the 140 $\mathrm{kDa}$ protein in ${ }^{35} \mathrm{~S}$-IP. Samples were run on $8 \%$ SDSPAGE and transferred to a nitrocellulose filter. The filter was probed by rabbit anti-RHA antiserum $(1: 2,000$, a gift from Jun-Qi Yang and Michael B Mathews, University of Medicine and Dentistry of New Jersey, Newark, NJ, USA) [13] followed by 1:2,000 horseradish peroxidase-labeled goat IgG $\mathrm{F}\left(\mathrm{ab}^{\prime}\right)_{2}$ anti-rabbit IgG ( $\gamma$-chain- and lightchain-specific; SouthernBiotech, Birmingham, AL, USA) and developed using SuperSignal West Pico Chemiluminescent Substrate (Pierce, Rockford, IL, USA).

\section{Quantification of anti-RHA antibody levels}

Levels of anti-RHA were estimated and analyzed using the Storm Phosphorimager and images were obtained on a storage phosphor screen (Amersham Biosciences, now part of GE Healthcare, Little Chalfont, Buckinghamshire, (that is, the sum of the values of the pixels in the image or selection; this is equivalent to the product of the area and the mean gray value) [14] of the RHA on a phosphorimage was calculated using ImageJ software (National Institutes of Health, Bethesda, MD, USA).

\section{Enzyme-linked immunosorbent assay}

Sera were tested for IgG anti-U1RNP/Sm, ribosomal $\mathrm{P}$ (P peptide), dsDNA, and $\beta 2$ glycoprotein I ( $\beta 2 \mathrm{GPI})$ (a gift from Junichi Kaburaki, Tokyo Electric Power Company Hospital, Tokyo, Japan) antibodies by enzyme-linked immunosorbent assay (ELISA) as described $[15,16]$. P peptide was $\mathrm{COOH}$-terminal 22 amino acids of human P0 protein [17]. dsDNA was purified using S1 nuclease as described [15]. Anti-U1RNP/Sm antigen-capture ELISA was performed as described [16]. Briefly, microtiter plates (Immobilizer Amino ${ }^{\mathrm{Tm}}$; Nalge Nunc, Rochester, NY, USA) 
were coated with $3 \mu \mathrm{g} / \mathrm{mL}$ mouse monoclonal antibodies (mAbs) 2.73 (IgG2a, anti-U1-70k) [10]. The left half of the plate was incubated with $\mathrm{K} 562$ cell lysate $(50 \mu \mathrm{L} /$ well, $4 \times 10^{7} / \mathrm{mL}$ ), and the right half was incubated with the blocking buffer as control. After the plate was washed, an identical set of samples and serially diluted standard serum (1:500 to serial 1:5 dilutions) were added to the left and right halves (control for reactivity against mouse IgG) of the plate. Serum samples were tested at 1:500 and 1:2,500 dilutions, and data from the latter were used for the analysis. Plates were washed with Tris-buffered saline/ Tween20, incubated with alkaline phosphatase-conjugated mouse mAbs to human IgG (Sigma-Aldrich, St. Louis, MO, USA) (1:1,000 dilution), and developed. The optical density (OD) of $405 \mathrm{~nm}$ of wells was converted into units based on the standard curve, and the units of the corresponding right half (without U1RNP/Sm antigens) were subtracted from the left half (with antigens) using SoftMax Pro 4.3 software (Molecular Devices Corporation, Sunnyvale, CA, USA) [15]. For the detection of anti-P peptide, dsDNA, and $\beta 2 \mathrm{GPI}$, microtiter plates were incubated with 1 to $3 \mu \mathrm{g} / \mathrm{mL}$ of the appropriate antigens, and ELISA was performed as described previously using 1:500 diluted sera. ODs were converted into units as described using the appropriate standard [15].

\section{Statistical analysis}

All statistical analysis was performed using Prism 5.0 for Macintosh (GraphPad Software, Inc., San Diego, CA, USA). The Fisher exact test and the Mann-Whitney test or Student $t$ test were used to analyze prevalence and levels, respectively, of autoantibodies and other data.

\section{Results}

A previous study suggested that anti-RHA was associated with an early stage of SLE within a few years of diagnosis [4]. Consistent with this observation, the levels of anti-RHA dramatically decreased over time. Studies in mouse models suggested that the environment for the production of anti-RHA was distinct from that of anti-small nuclear ribonucleoproteins (anti-snRNPs) or anti-Su (Ago2) [12,18]. Opposite kinetics of production of anti-RHA versus anti-snRNPs or anti-ribosomal P, observed in some human cases, may be reminiscent of these observations $[4,7]$. Thus, we examined whether these findings in the previous human study performed in an American (mainly Caucasian) population [4] also apply to Mexican patients with SLE and whether antiRHA and anti-snRNPs have a negative correlation.

\section{Screening of anti-RHA antibodies}

Anti-RHA antibodies were screened based on the IP of the $140-\mathrm{kDa}$ protein using ${ }^{35} \mathrm{~S}$-methionine-labeled $\mathrm{K} 562$ cell extract as described [4]. Sera selected were run along with the prototype sera to verify the identical mobility (Figure 1a). Several sera with strong reactivities showing typical degradation patterns (white arrowheads, see lanes RHA, 4, 5, 7, and 10) were clearly anti-RHA; however, it is possible that there are other proteins that co-migrate with RHA. Thus, IP-WB using rabbit antiRHA serum was also performed to verify the identity of proteins immunoprecipitated by each serum (Figure 1b). All 14 sera initially selected by IP were positive by IPWB, confirming that the sera indeed had anti-RHA. Clinical and immunological characteristics of these 14 patients were compared with those of anti-RHAnegative patients.

\section{Prevalence of anti-RHA antibodies and stage of the disease}

Anti-RHA was found in 23\% (14/62) in this cohort of Mexican patients, a prevalence that was greater than that of anti-Sm (13\%) (Table 1) and much higher than that of anti-RHA (6\%) reported in American patients [4], whereas the prevalence of other specificities did not seem to be different from other reports in SLE.

The production of anti-RHA was associated with an early stage of SLE in American patients [4]. To examine whether this applies to Mexican patients, the prevalence of anti-RHA was compared in groups classified based on the years between diagnosis and screening test (Table 2). Two of four patients within a year of diagnosis had anti-RHA; however, 9 out of 14 cases of antiRHA were after 5 years of diagnosis, suggesting that anti-RHA does not disappear in Mexican patients with SLE. This is in striking contrast to the Caucasian population [7]. Also, the prevalence of anti-RHA was the same as or higher than that of anti-Sm in patients even more than 5 or 10 years after diagnosis. These results were quite different from the pattern reported in the previous American study [4]. Distributions of age at diagnosis, age at anti-RHA test, and years between diagnosis and anti-RHA test were compared between antiRHA-positive (left in each panel) and -negative (right) patients (Figure 2a, b, and 2c, respectively). All showed no clear difference between anti-RHA $(+)$ and (-) groups.

\section{Levels of anti-RHA antibodies and stage of the disease and SLEDAI}

Next, whether the levels of anti-RHA in patients years after diagnosis are lower than those of patients with early-disease status was evaluated by comparing the intensity of RHA IP and years after diagnosis (Figure 2d). Although the linear regression analysis suggested a negative association between these two, it was not statistically significant. It appeared that the samples with very strong anti-RHA antibodies and the ones with weak anti-RHA 


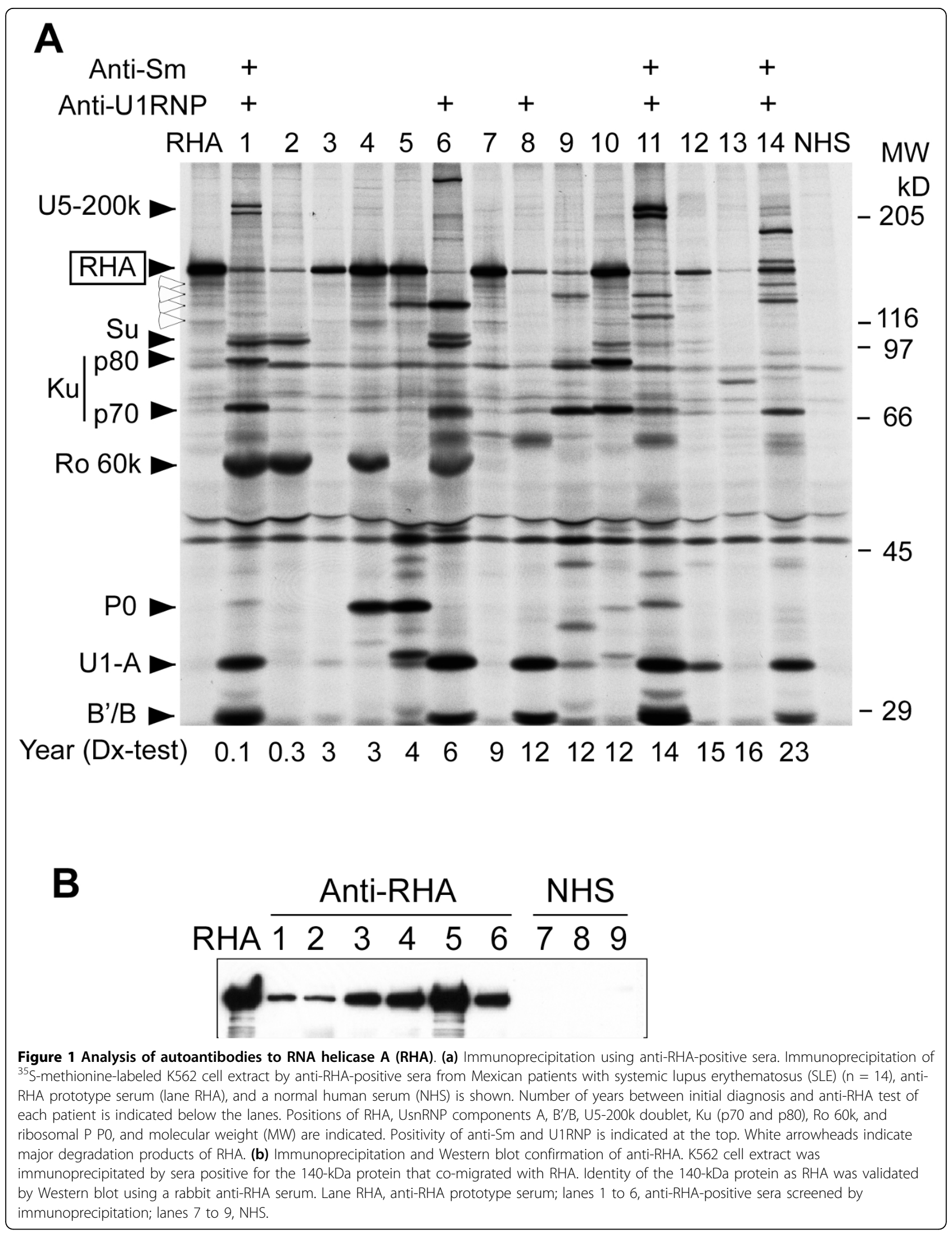


Table 1 Frequency of autoantibodies in Mexican patients with systemic lupus erythematosus

\begin{tabular}{lccc}
\hline & Total & Anti-RHA (+) & Anti-RHA (-) \\
\hline Number of patients & 62 & 14 & 48 \\
RHA & $23 \%(14 / 62)$ & & \\
U1RNP & $29 \%(18 / 62)$ & $36 \%(5 / 14)$ & $27 \%(13 / 48)$ \\
Sm & $13 \%(8 / 62)$ & $21 \%(3 / 14)$ & $10 \%(5 / 48)$ \\
Anti-Sm (+) among & $44 \%(8 / 18)$ & $60 \%(3 / 5)$ & $38 \%(5 / 13)$ \\
anti-U1RNP (+) & & & \\
Ribosomal P & $8 \%(5 / 62)$ & $14 \%(2 / 14)$ & $6 \%(3 / 48)$ \\
Ro & $39 \%(24 / 62)$ & $29 \%(4 / 14)$ & $42 \%(20 / 48)$ \\
La & $8 \%(5 / 62)$ & $0 \%(0 / 14)$ & $10 \%(5 / 48)$ \\
Ku & $6 \%(4 / 62)$ & $14 \%(2 / 14)$ & $4 \%(2 / 48)$ \\
Su & $24 \%(15 / 62)$ & $29 \%(4 / 14)$ & $23 \%(11 / 48)$ \\
RNAP ॥ & $10 \%(6 / 62)$ & $14 \%(2 / 14)$ & $8 \%(4 / 48)$ \\
\hline
\end{tabular}

Not significant between anti-RHA (+) and (-) groups for all specificities by Fisher exact test. RHA, RNA helicase A; RNAP II, RNA polymerase II.

Table 2 Frequency of anti-RHA and years from diagnosis

\begin{tabular}{lccc}
\hline $\begin{array}{l}\text { Years between } \\
\text { diagnosis and test }\end{array}$ & $\begin{array}{c}\text { Number of } \\
\text { patients }\end{array}$ & $\begin{array}{c}\text { Anti-RHA } \\
(\mathbf{n}=\mathbf{1 4})\end{array}$ & $\begin{array}{c}\text { Anti-Sm } \\
(\mathbf{n}=\mathbf{8})\end{array}$ \\
\hline 0 to less than 1 & 4 & $50 \%(2 / 4)$ & $75 \%(3 / 4)$ \\
1 to less than 2 & 5 & $0 \%(0 / 5)$ & $0 \%(0 / 5)$ \\
2 to less than 5 & 15 & $20 \%(3 / 15)$ & $0 \%(0 / 15)$ \\
5 to less than 10 & 17 & $12 \%(2 / 17)$ & $12 \%(2 / 17)$ \\
10 or more & 21 & $33 \%(7 / 21)$ & $14 \%(3 / 21)$ \\
\hline
\end{tabular}

RHA, RNA helicase $A$.

were both scattered throughout the different stages of the disease, suggesting that anti-RHA levels do not decrease dramatically, unlike in American patients in the previous report [4].

Detailed information on SLE classification criteria was available from 12 anti-RHA (+) and 42 anti-RHA (-) patients. The prevalence of each SLE criteria was compared between anti-RHA (+) and (-) groups to examine whether anti-RHA (+) SLE had unique clinical features. The prevalence of all criteria items appeared to be similar between groups (data not shown). Whether antiRHA (+) SLE had different disease activity was evaluated by comparing SLEDAI between anti-RHA (+) and (-) patients, but no clear difference was found (Figure 2e). No correlation between the levels of anti-RHA antibodies and disease activity was observed (Figure $2 \mathrm{f}$ ).

Levels of various autoantibodies and anti-RHA antibodies The prevalence of coexisting autoantibodies was not significantly different between anti-RHA-positive and -negative patients (Table 1). Levels of anti-U1RNP/Sm, -ribosomal P (P peptide), dsDNA, and $\beta 2 \mathrm{GPI}$ antibodies by ELISA were compared between anti-RHA-positive and -negative cases (Figure 3a-d); however, the difference was not apparent for any of these specificities.
The levels of anti-RHA quantified by phosphorimager and those of anti-U1RNP/Sm by ELISA were compared. Although the subjects with high levels of anti-RHA may be more common in the anti-U1RNP/Sm-negative group, the difference did not reach statistical significance $(P=0.07$ by Student $t$ test) (Figure $3 \mathrm{e})$. None of the anti-U1RNP/Sm $(+)$ cases $(0 / 5)$ had an anti-RHA integrated density of greater than 30,000 versus $56 \%$ (5/ $9)$ in the anti-U1RNP/Sm (-) group ( $P=0.086$ by Fisher exact test). There was a trend of negative correlation between levels of anti-RHA and anti-U1RNP/Sm; however, it was not statistically significant (Figure $3 f$ ).

\section{Discussion}

Anti-Sm antibody is a well-established serological marker of SLE and is one of the minor criteria under immunological disorders of the SLE classification criteria [3]. However, it is found in only approximately $15 \%$ of SLE patients and in particular it is uncommon in Caucasians [19]. Thus, an additional serological marker specific for SLE should be clinically useful. Anti-RHA has recently been reported as a new serological marker of SLE in the US [4]. The rates of prevalence in the previous study were $6 \%$ in the general SLE population, approximately $6 \%$ in Caucasians and African-Americans, and $12 \%$ in the Latin population; however, only 3 out of 25 Latin patients were positive. The present study showed a much higher prevalence of anti-RHA: 23\% in Mexican patients with SLE. Although anti-RHA appears specific for SLE in the previous study regardless of the race, the number of Latin patients was relatively small [4]. Disease specificity of anti-RHA in other ethnicities, including Mexicans, will need to be established in future studies. In contrast to previous data [4], the presence of anti-RHA was not skewed toward patients in an early stage of the disease in the current study (Table 1). A comparison of years between diagnosis and anti-RHA test versus levels of anti-RHA (Figure $2 \mathrm{~d}$ ) did not show a clear negative correlation, suggesting a relatively stable production of anti-RHA over time in Mexican patients. There are several potential explanations for the discrepancy. One possibility is the racial difference. The previous study on anti-RHA-positive SLE included 8 Caucasians but only 3 African-Americans and 3 Latin patients, indicating that the data were much affected by the characteristics of Caucasian anti-RHA-positive SLE patients. A recent analysis of the same study population showed that the majority of Caucasian patients with anti-RHA were at an early stage of SLE; 5 out of 8 antiRHA patients were within one year of diagnosis [7]. However, this may not be the case for other races, a circumstance that may potentially explain the difference.

A second difference is a distribution of different stages of SLE patients for reasons that are not clear; the 

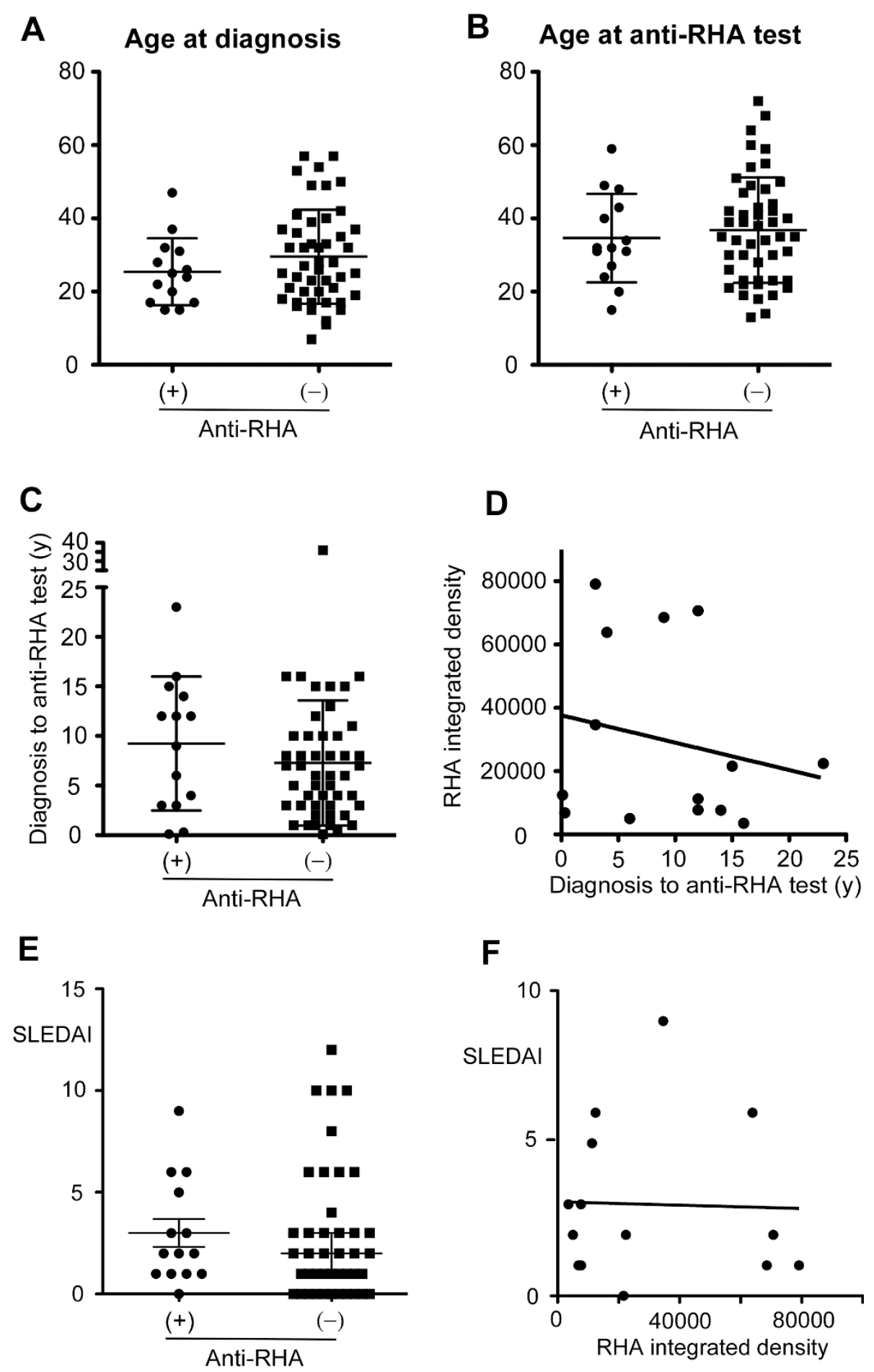

Figure 2 Age at diagnosis, age at anti-RNA helicase A (anti-RHA) test, and years between diagnosis and anti-RHA test. Demographic data of anti-RHA-positive $(n=14)$ and -negative $(n=48)$ systemic lupus erythematosus (SLE) patients were compared. (a) Age at diagnosis. (b) Age at anti-RHA test. (c) Years from diagnosis to anti-RHA test. (d) Years from diagnosis to anti-RHA test versus levels of anti-RHA. (e) Systemic Lupus Erythematosus Disease Activity Index (SLEDAI) in anti-RHA (+) versus (-) patients. (f) Correlation of SLEDAl and levels of anti-RHA. Anti-RHA levels were measured as integrated density of RHA protein band using phosphorimager as described in Materials and methods. $y$, years. 


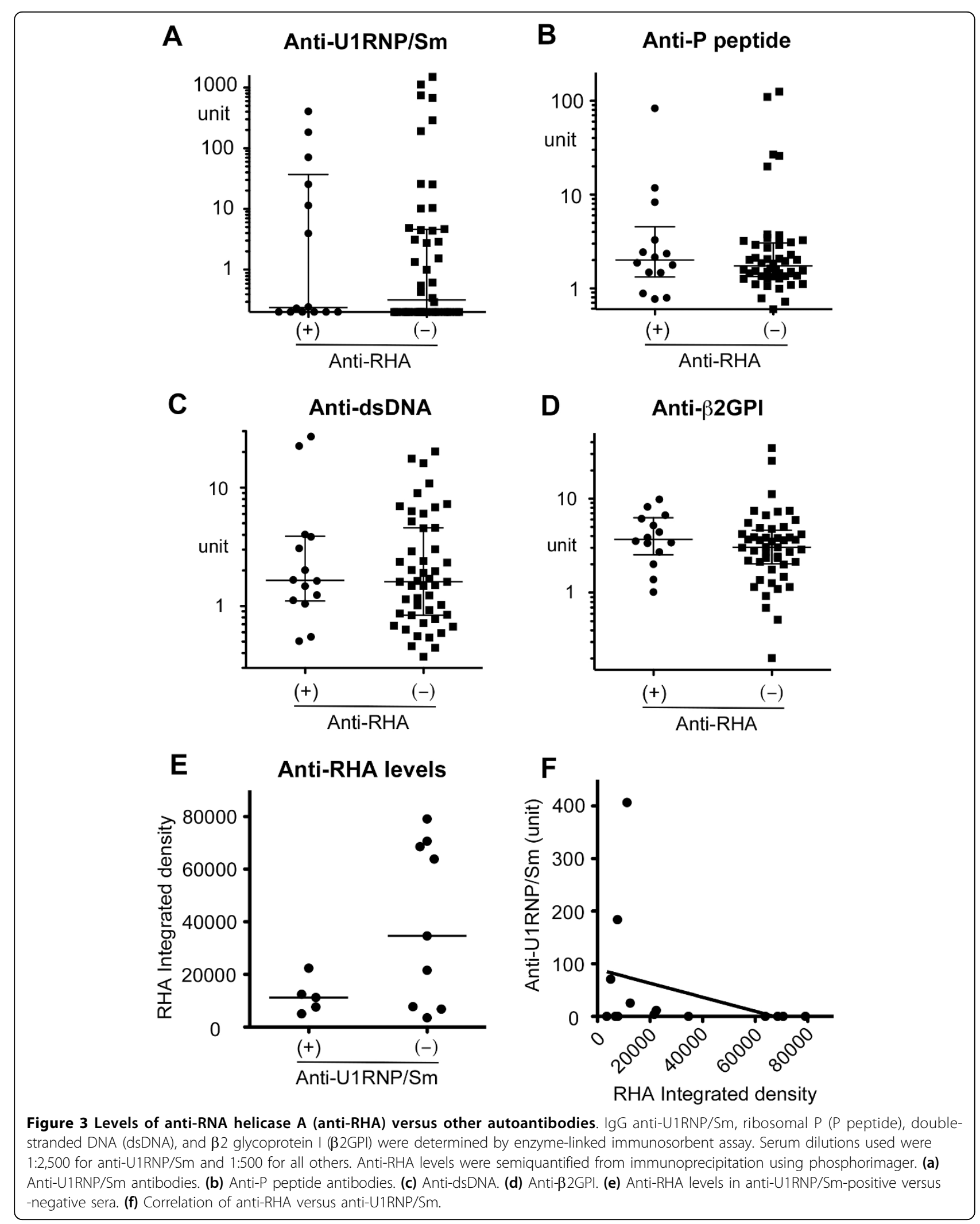


previous American study had a large percentage of patients in an early stage of SLE [4]. In the previous study, the percentage of patients within 1 or 2 years into the disease was nearly twice that of the present study (13\% versus $7 \%, 27 \%$ versus $15 \%$, within 1 year and 2 years, respectively). Although the reduction of anti-RHA levels did not appear to be a simple result of immunosuppressive therapy, current and historical treatment may also have effects on the data mentioned above. These points should be addressed in future studies with a large number of patients from different ethnicities.

A hydrocarbon oil pristane induces autoantibodies to snRNPs, ribosomal P, and Ago2/Su in normal mice $[20,21]$; however, it inhibits the production of anti-RHA antibodies in two strains of mice that spontaneously produce anti-RHA: NZB/W F1 [12] and CBA/n (x-linked immunodeficiency) [18]. In the former, pristane induced anti-snRNP and anti-Ago2/Su antibodies [12]. Human anti-RHA-positive cases that newly developed anti-snRNPs or -ribosomal P antibodies while their anti-RHA levels drop significantly [4] appear to be reminiscent of the observations in animal models. Thus, it seems reasonable to hypothesize that the environment or stage of the disease that is preferable for the production of anti-RHA is not ideal for the production of other specificities. Although the difference was not statistically significant ( $P=0.07$, Student $t$ test) (Figure 3e), five cases with the highest levels of anti-RHA were in the anti-snRNP-negative group. These may be the cases that are going to 'switch' the specificities from anti-RHA to anti-snRNPs later, like the previously described cases [4]. Factors that are responsible for the production of anti-RHA or switching from anti-RHA to anti-snRNPs in humans are not known; however, in animal models of pristane injection, which switches autoantibody specificity from anti-RHA to anti-snRNP production, type I interferon (I-IFN) [22,23] and Th1 cytokine shifting are induced [12]. Thus, switching of autoantibody specificities in humans may also involve changes in cytokine balance, in particular Th1 cytokine or I-IFN production, or Toll-like receptor (TLR) 7 stimulation since the production of pristane-induced anti-snRNPs in animal models is dependent on I-IFN [24] and TLR7 [25]. Environmental factors such as viral infection may trigger this type of change via stimulation of TLRs or via a TLR-independent mechanism of I-IFN induction [26]. Although the production of lupus autoantibodies is generally considered an event prior to typical clinical manifestation [27], it is of interest that $10 \%$ to $15 \%$ of autoantibodies develop after the diagnosis, in particular within a year of diagnosis [1]. The development of anti-snRNPs after steroid treatment reported in clinically MCTD (mixed connective tissue disease) patients $[28,29]$ is interesting when considering a role of treatment as a trigger to change the environment of autoantibody production, although differentiating the natural course from induction by steroids is virtually impossible. The identification of mechanisms of induction and regulation of various autoantibodies may help develop a strategy of therapeutic regulation of autoantibody production.

\section{Conclusions}

The present study reports a high prevalence of antiRHA in Mexican patients with SLE. The detection of SLE-specific autoantibodies in addition to anti-Sm should be clinically helpful, in particular in the population of patients with a low prevalence of anti-Sm. Patients with high levels of anti-RHA appear to be more common among anti-snRNP-negative patients. A strong association of anti-RHA with an early stage of SLE was not apparent in the Mexican population, possibly due to the relatively stable production of anti-RHA over time. Possible differences in clinical significance of anti-RHA in different races should be clarified in future studies.

\section{Abbreviations}

$\beta 2 \mathrm{GPI}$ : $\beta 2$ glycoprotein I; ACR: American College of Rheumatology; Ago2: argonaute 2; dsDNA: double-stranded DNA; ELISA: enzyme-linked immunosorbent assay; I-IFN: type I interferon; IP: immunoprecipitation; mAb: monoclonal antibody; OD: optical density; RHA: RNA helicase A; SLE: systemic lupus erythematosus; SLEDAl: Systemic Lupus Erythematosus Disease Activity Index; snRNP: small nuclear ribonucleoprotein; TLR: Toll-like receptor; WB: Western blot.

\section{Acknowledgements}

This study was supported by CONACyT-SEP Ciencia Básica grant 51353 Universidad de Guadalajara agreement 25473 to MVDM. MS is supported in part by a grant from Lupus Foundation of America, Inc. EKLC is supported in part by National Institutes of Health grant Al47859.

\section{Author details}

'Departamento de Biología Molecular y Genómica, Instituto de Investigación en Reumatología y del Sistema Músculo Esquelético, Centro Universitario de Ciencias de la Salud, Universidad de Guadalajara, Sierra Mojada 950, Guadalajara, Jalisco, CP 44340, México. ²División de Medicina Interna, Departamento de Reumatología, Hospital Civil 'Dr. Juan I. Menchaca', Salvador de Quevedo y Zubieta N 750, CP 44340, Guadalajara, Jalisco, México. ${ }^{3}$ Departamento de Inmunología y Reumatología del Hospital General de Occidente, Secretaría de Salud Jalisco, Av. Zoquipan 1050, CP 45100, Zapopan, Jalisco, México. ${ }^{4}$ División de Investigación, Hospital de Especialidades, CMNO, IMSS, and Departamento de Fisiología, CUCS,

Universidad de Guadalajara, Sierra Mojada 950, CP 44340, Guadalajara, Jalisco, México. ${ }^{5}$ Departamento de Biología Molecular y Genómica, Instituto de Biología Molecular y Genómica, Centro Universitario de Ciencias de la Salud, Universidad de Guadalajara, Sierra Mojada 950, Guadalajara, Jalisco, CP 44340, México. ${ }^{6}$ Servicio de Medicina-Interna-Reumatología, Hospital Regional 110, IMSS, Guadalajara, Jalisco, México. ${ }^{7}$ Division of Rheumatology and Clinical Immunology, Department of Medicine, University of Florida, 1600 SW Archer Road, Gainesville, FL 32610-0424, USA. ${ }^{8}$ Department of Oral Biology, University of Florida, 1600 SW Archer Road, Gainesville, FL 32610-0424, USA. ${ }^{9}$ Department of Pathology, Immunology, and Laboratory Medicine, University of Florida, 1600 SW Archer Road, Gainesville, FL 32610-0221, USA.

\section{Authors' contributions}

MVDM and MS designed the study, performed experiments, and wrote the manuscript. CAPS, JFMV, GOB, EOR, RENH, MSP, JAB, JIGN, and LGL helped 
perform experiments and interpret data. JYFC and EKLC helped perform experiments, interpret data, and write the manuscript. All authors read and approved the final manuscript.

\section{Competing interests}

The authors declare that they have no competing interests.

Received: 18 September 2009 Revisions requested: 5 November 2009 Revised: 17 December 2009 Accepted: 8 January 2010

Published: 8 January 2010

\section{References}

1. Satoh M, Chan EK, Sobel ES, Kimpel DL, Yamasaki Y, Narain S, Mansoor R, Reeves WH: Clinical implication of autoantibodies in patients with systemic rheumatic diseases. Expert Rev Clin Immunol 2007, 3:721-738.

2. Satoh M, Vazquez-Del Mercado M, Chan EK: Clinical interpretation of antinuclear antibody tests in systemic rheumatic diseases. Mod Rheumatol 2009, 19:219-228.

3. Tan EM, Cohen AS, Fries JF, Masi AT, McShane DJ, Rothfield NF, Schaller JG, Talal N, Winchester RJ: The 1982 revised criteria for the classification of systemic lupus erythematosus. Arthritis Rheum 1982, 25:1271-1277.

4. Yamasaki Y, Narain S, Yoshida H, Hernandez L, Barker T, Hahn PC, Sobel ES, Richards HB, Chan EK, Reeves WH, Satoh M: Autoantibodies to RNA helicase A: a new serological marker of early lupus. Arthritis Rheum 2007, 56:596-604.

5. Colla E, Lee SD, Sheen MR, Woo SK, Kwon HM: TonEBP is inhibited by RNA helicase A via interaction involving the E'F loop. Biochem J 2006, 393:411-419.

6. Takeda Y, Caudell P, Grady G, Wang G, Suwa A, Sharp GC, Dynan WS, Hardin JA: Human RNA helicase $A$ is a lupus autoantigen that is cleaved during apoptosis. J Immunol 1999, 163:6269-6274.

7. Chan JYF, Yoshida H, Mizutani A, Yamasaki Y, Sobel ES, Chan EKL, Reeves WH, Satoh M: Autoantibodies to RNA helicase A as a new serologic marker of early SLE. From Etiopathogenesis to the Prediction of Autoimmune Diseases: Relevance of Autoantibodies Autoantigens, Autoantibodies and Autoimmunity Proceedings 9th Dresden Symposium on Autoantibodies Lengerich, Germany: Pabst Science PublishersConrad K, Chan EKL, Fritzler MJ, Sack U, Shoenfeld Y, Wiik A 2009, 61-70.

8. Guzman J, Cardiel MH, Arce-Salinas A, Sanchez-Guerrero J, AlarconSegovia D: Measurement of disease activity in systemic lupus erythematosus. Prospective validation of 3 clinical indices. $J$ Rheumatol 1992, 19:1551-1558.

9. Gladman DD, Urowitz MB, Goldsmith CH, Fortin P, Ginzler E, Gordon C, Hanly JG, Isenberg DA, Kalunian K, Nived O, Petri M, Sanchez-Guerrero J, Snaith M, Sturfelt G: The reliability of the Systemic Lupus International Collaborating Clinics/American College of Rheumatology Damage Index in patients with systemic lupus erythematosus. Arthritis Rheum 1997, 40:809-813.

10. Satoh M, Langdon JJ, Hamilton KJ, Richards HB, Panka D, Eisenberg RA, Reeves WH: Distinctive immune response patterns of human and murine autoimmune sera to U1 small nuclear ribonucleoprotein C protein. J Clin Invest 1996, 97:2619-2626.

11. Okano Y, Targoff IN, Oddis CV, Fujii T, Kuwana M, Tsuzaka K, Hirakata M, Mimori T, Craft J, Medsger JTA: Anti-U5 small nuclear ribonucleoprotein (snRNP) antibodies: a rare anti-U snRNP specificity. Clin Immunol Immunopathol 1996, 81:41-47.

12. Yoshida H, Satoh M, Behney KM, Lee C-G, Richards HB, Shaheen VM, Yang JQ, Singh RR, Reeves WH: Effect of an exogenous trigger on the pathogenesis of lupus in NZB $\times$ NZW (F1) mice. Arthritis Rheum 2002, 46:2235-2244.

13. Liao HJ, Kobayashi R, Mathews MB: Activities of adenovirus virusassociated RNAs: purification and characterization of RNA binding proteins. Proc Natl Acad Sci USA 1998, 95:8514-8519.

14. Analyze Menu, Documentation, ImageJ. http://rsb.info.nih.gov/ij/docs/ menus/analyze.html.

15. Yamasaki Y, Narain S, Hernandez L, Barker T, Ikeda K, Segal MS, Richards HB, Chan EK, Reeves WH, Satoh M: Autoantibodies against the replication protein $A$ complex in systemic lupus erythematosus and other autoimmune diseases. Arthritis Res Ther 2006, 8:R111-120

16. Palafox Sánchez CA, Satoh M, Chan EK, Carcamo WC, Muñoz Valle JF, Orozco Barocio G, Oregon Romero E, Navarro Hernández RE, Salazar
Páramo M, Cabral Castañeda A, Vázquez Del Mercado M: Reduced IgG anti-small nuclear ribonucleoproteins autoantibody production in systemic lupus erythematosus patients with positive IgM anticytomegalovirus antibodies. Arthritis Res Ther 2009, 11:R27.

17. Magsaam J, Gharavi AE, Parnassa AP, Weissbach H, Brot N, Elkon KB: Quantification of lupus anti-ribosome $P$ antibodies using a recombinant P2 fusion protein and determination of the predicted amino acid sequence of the autoantigen in patients' mononuclear cells. Clin Exp Immunol 1989, 76:165-171.

18. Satoh M, Mizutani A, Behney KM, Kuroda Y, Akaogi J, Yoshida H, Nacionales DC, Hirakata M, Ono N, Reeves WH: X-linked immunodeficient mice spontaneously produce lupus-related anti-RNA helicase $A$ autoantibodies, but are resistant to pristane-induced lupus. Int Immunol 2003, 15:1117-1124.

19. Wang J, Satoh M, Kabir F, Shaw M, Domingo MA, Mansoor R, Behney KM, Dong $X$, Lahita RG, Richards HB, Reeves WH: Increased prevalence of autoantibodies to ku antigen in African American versus white patients with systemic lupus erythematosus. Arthritis Rheum 2001, 44:2367-2370.

20. Satoh $M$, Reeves WH: Induction of lupus-associated autoantibodies in $\mathrm{BALB} / \mathrm{C}$ mice by intraperitoneal injection of pristane. J Exp Med 1994, 180:2341-2346.

21. Satoh $M$, Hamilton KJ, Ajmani AK, Dong X, Wang J, Kanwar Y, Reeves WH: Autoantibodies to ribosomal $\mathrm{P}$ antigens with immune complex glomerulonephritis in SJL mice treated with pristane. J Immunol 1996, 157:3200-3206

22. Nacionales DC, Kelly KM, Lee PY, Zhuang H, Li Y, Weinstein JS, Sobel E, Kuroda Y, Akaogi J, Satoh M, Reeves WH: Type I interferon production by tertiary lymphoid tissue developing in response to 2,6,10,14-tetramethylpentadecane (pristane). Am J Pathol 2006, 168:1227-1240.

23. Lee PY, Weinstein JS, Nacionales DC, Scumpia PO, Li Y, Butfiloski E, van Rooijen N, Moldawer L, Satoh M, Reeves WH: A novel type I IFN-producing cell subset in murine lupus. J Immunol 2008, 180:5101-5108.

24. Nacionales DC, Kelly-Scumpia KM, Lee PY, Weinstein JS, Lyons R, Sobel E, Satoh $M$, Reeves WH: Deficiency of the type I interferon receptor protects mice from experimental lupus. Arthritis Rheum 2007, 56:3770-3783.

25. Lee PY, Kumagai Y, Li Y, Takeuchi O, Yoshida H, Weinstein J, Kellner ES, Nacionales D, Barker T, Kelly-Scumpia K, van Rooijen N, Kumar H, Kawai T, Satoh M, Akira S, Reeves WH: TLR7-dependent and Fc\{gamma\}Rindependent production of type I interferon in experimental mouse lupus. J Exp Med 2008, 205:2995-3006.

26. Takeuchi O, Akira S: Recognition of viruses by innate immunity. Immunol Rev 2007, 220:214-224.

27. Arbuckle MR, McClain MT, Rubertone MV, Scofield RH, Dennis GJ, James JA, Harley JB: Development of autoantibodies before the clinical onset of systemic lupus erythematosus. N Engl J Med 2003, 349:1526-1533.

28. Alarcon-Segovia D: Mixed connective tissue disease. Appearance of antibodies to ribonucleoprotein following corticosteroid treatment. $J$ Rheumatol 1979, 6:694-699.

29. Ellman MH, Pachman L, Medof ME: Raynaud's phenomenon and initially seronegative mixed connective tissue disease. J Rheumatol 1981, 8:632-634.

\section{doi:10.1186/ar2905}

Cite this article as: Vázquez-Del Mercado et al.: High prevalence of autoantibodies to RNA helicase A in Mexican patients with systemic lupus erythematosus. Arthritis Research \& Therapy 2010 12:R6. 